\title{
Verbal Fluency Is Affected by Altered Brain Lateralization in Adults Who Were Born Very Preterm
}

\author{
DChieh-En Jane Tseng, ${ }^{1}$ DSean Froudist-Walsh, ${ }^{1,2}$ Jasmin Kroll, ${ }^{1}$ Vyacheslav Karolis, ${ }^{1}$ Philip J. \\ Brittain, ${ }^{1}$ Nadia Palamin, ${ }^{1,3}$ Hayley Clifton, ${ }^{1}$ Serena J. Counsell, ${ }^{4}$ Steven C. R. Williams, ${ }^{5}$ Robin M. \\ Murray, ${ }^{1}$ and Chiara Nosarti ${ }^{1,4}$
}

\author{
https://doi.org/10.1523/ENEURO.0274-18.2018
}

\begin{abstract}
${ }^{1}$ Department of Psychosis Studies, Institute of Psychiatry, Psychology and Neuroscience, King's College London, London, United Kingdom SE5 8AF, 22Center for Neural Science, New York University, New York, NY 10003, ${ }^{3}$ Department of Developmental and Social Psychology (DPSS), University of Padova, 35131, Padova, Italy, ${ }^{4}$ Centre for the Developing Brain, Division of Imaging Sciences \& Biomedical Engineering, King's College London, London, United Kingdom SE1 7EH, and ${ }^{5}$ Centre for Neuroimaging Sciences, Institute of Psychiatry, Psychology and Neuroscience, King's College London, London, United Kingdom SE5 8AF
\end{abstract}

\begin{abstract}
Language difficulties have been reported in children and adolescents who were born very preterm ( $<32$ weeks' gestation) and associated with an atypical lateralization of language processing, i.e., increased right-hemispheric engagement. This study used functional magnetic resonance imaging (fMRI) and spherical deconvolution tractography to study the hemodynamic responses associated with verbal fluency processing (easy and hard letter trials) and verbal fluency-related white matter fiber tracts in 64 very preterm born adults and 36 adult controls (mean age: 30 years). Tractography of the arcuate fasciculus (AF) and frontal aslant tract (FAT) was performed. Tracts were quantified in terms of mean volume, hindrance modulated orientational anisotropy, and lateralization, assessed using a laterality index (LI) to indicate hemispheric dominance. During verbal fluency fMRI, very preterm participants displayed decreased hemodynamic response suppression in both the Easy $>$ Rest and Hard $>$ Rest conditions, compared to controls, in superior temporal gyrus (STG), insula, thalamus, and sensorimotor cortex, particularly in the right hemisphere. At the whole-group level, decreased hemodynamic response suppression in the right sensorimotor cortex was associated with worse on-line performance on the hard letter trials. Increased left-laterality in the AF was present alongside increased right hemispheric hemodynamic response suppression in controls. When only right-handed participants were considered, decreased hemodynamic response suppression in the right STG during hard letter trials was related to weaker left and right FAT white
\end{abstract}

\section{Significance Statement}

This is the first study to use both functional and structural magnetic resonance imaging (MRI) to assess the neuroanatomy of verbal fluency in very preterm born adults. Less suppression of brain activation was observed in very preterm adults compared to controls in several brain regions during completion of both easy and hard verbal fluency trials. Furthermore, across all subjects, decreased brain activity suppression in the right sensorimotor cortex was associated with worse on-line performance on the hard letter trials. Increased left-laterality in the arcuate fasciculus (AF), a language-related white matter tract, was present alongside increased right hemispheric brain activity suppression in controls. These findings suggest that alterations in the typical development of left-lateralization in very preterm individuals are still present in adulthood. 
matter integrity in the preterm group only. These results show that verbal fluency is affected by altered functional lateralization in adults who were born very preterm.

Key words: fMRI; lateralization; verbal fluency; very preterm

\section{Introduction}

During the third trimester of pregnancy, the fetal brain more than doubles in size and the volume of cortical gray matter increases approximately four-fold (Hüppi et al., 1998). At the same time, thalamocortical axons are reaching the cortical plate and callosal white matter connections are spreading across the subplate zone (Kostovíc and Jovanov-Milosevíc, 2006). These processes establish the neural foundation for the development of cognitive and motor functions. Very preterm birth $(<32$ weeks' gestation) can thus lead to a complex pattern of exogenous and endogenous insults (Volpe, 2009), which result in alterations to structural and functional brain development (Smyser et al., 2010; Ball et al., 2015).

In terms of cognitive outcomes, very preterm born individuals have shown poorer verbal fluency performance than controls (Aarnoudse-Moens et al., 2009; Nam et al., 2015). Verbal fluency involves strategic search and retrieval processes from lexicon and semantic memory (Sauzéon et al., 2004), which tests both verbal ability and executive control. Impairments in such domains are believed to affect academic achievement and may lead to poorer occupational prospects (Kroll et al., 2017). While receptive language abilities have been shown to improve with age in very preterm children, deficits in expressive language functions seem to persist into adolescence (Luu et al., 2011). Using functional magnetic resonance imaging (fMRI), it was previously demonstrated that while completing a verbal fluency task with different cognitive loads, very preterm young adults showed differences in hemodynamic response compared to controls predominantly in frontal, parietal, temporal, and subcortical regions (Nosarti et al., 2009; Kalpakidou et al., 2014).

Several studies described structural and functional brain asymmetries of language-related regions during typical development (Sowell et al., 2002; Dehaene-

Received July 12, 2018; accepted November 25, 2018; First published March $5,2019$.

The authors declare no competing financial interests.

Author contributions: C.-E.J.T., S.F.-W., S.J.C., S.C.R.W., R.M.M., and C.N. designed research; C.-E.J.T., S.F.-W., J.K., V.K., P.J.B., and C.N. performed research; C.-E.J.T., N.P., H.C., and C.N. analyzed data; C.-E.J.T., S.F.-W., J.K., V.K., P.J.B., S.J.C., S.C.R.W., R.M.M., and C.N. wrote the paper.

The work was supported by the Medical Research Council, UK Grant $\mathrm{MR} / \mathrm{K} 004867 / 1$

Acknowledgements: We thank our study participants for their continuing help. We also thank the National Institute for Health Research (NIHR) Biomedical Research Center at South London and Maudsley NHS Foundation Trust and King's College London for supporting the neuroimaging facilities used in our study.

Correspondence should be addressed to Chieh-En Jane Tseng at ctseng4@mgh.harvard.edu.

https://doi.org/10.1523/ENEURO.0274-18.2018

Copyright (C) 2019 Tseng et al.

This is an open-access article distributed under the terms of the Creative Commons Attribution 4.0 International license, which permits unrestricted use, distribution and reproduction in any medium provided that the original work is properly attributed.
Lambertz et al., 2006a,b; Friederici et al., 2011; Kasprian et al., 2011). A deeper right superior temporal sulcus and larger left temporal lobe was observed as early as 23 weeks' gestation (Kasprian et al., 2011). This asymmetry continues to develop postnatally, with perisylvian sulcal asymmetries being more prominent in adults than in children (Sowell et al., 2002). fMRI studies demonstrated dominant left-hemispheric responses during processing of language-related auditory stimuli in newborn infants (Dehaene-Lambertz et al., 2006a,b). However, a lack of lateralization in language related regions was observed in very preterm infants at term equivalent age compared to term control infants (Kwon et al., 2015).

Increased left-lateralization in language homologs may reflect typical maturational processes from childhood to adulthood (Friederici et al., 2011). This process may be altered in very preterm individuals, as increased righthemispheric engagement was found in very preterm adolescents during a verbal task (Gozzo et al., 2009; Myers et al., 2010), suggesting the use of alternate neural pathways for language processing. However, this alternative neural pathway could be suboptimal, given the finding that stronger right-lateralization in very preterm adolescents was associated with poorer language performance (Scheinost et al., 2015).

Measures of language have also been related to microstructural integrity of white matter connections in preterm samples, and similarly to fMRI studies, show a bilateral language network (Mullen et al., 2011; Feldman et al., 2012). The arcuate fasciculus (AF) and the frontal aslant tract (FAT) are two white matter tracts that are involved in the verbal component of verbal fluency. The AF connects the superior temporal gyrus (STG) to the inferior frontal gyrus (IFG) and has long been recognized for its involvement in language. The FAT is a recently identified pathway that connects the supplementary motor area to the IFG (Catani et al., 2012). It has been shown to be involved in speech fluency in adults who stutter (Kronfeld-Duenias et al., 2016) and individuals with primary progressive aphasia (Catani et al., 2013).

This study tested the following hypotheses: (1) during completion of a verbal fluency task, very preterm adults would display a greater recruitment of homologous language-related regions in the right hemisphere in comparison to controls; (2) very preterm adults would exhibit smaller volume and hindrance modulated orientational anisotropy (HMOA; a tract-specific characterization of white matter microstructure) and decreased leftlateralization in the structural indices of the AF and FAT tracts compared to controls; and (3) increased right hemispheric hemodynamic response in very preterm adults would be associated with worse verbal fluency performance and stronger right-lateralization in white matter structural indices. We further explored possible betweengroup differences in the associations between fMRI data and task performance and white matter tract measure- 
Table 1. Participants' neonatal and socio-demographic variables

\begin{tabular}{|c|c|c|c|c|}
\hline & $\begin{array}{l}\text { Very preterm } \\
(n=64)\end{array}$ & $\begin{array}{l}\text { Control } \\
(n=36)\end{array}$ & Test statistic & $p$ value \\
\hline Age (mean $\pm S D)$ & $31.53 \pm 2.44$ & $30.47 \pm 6.36$ & $U=806.0$ & 0.013 \\
\hline Sex $(M / F)$ & $36 / 28$ & $21 / 15$ & $\chi^{2}=0.041$ & 1.000 \\
\hline \multicolumn{5}{|l|}{ IQ } \\
\hline Verbal IQ & $97 \pm 18.37$ & $107.73 \pm 16.33$ & $U=1159.5$ & 0.017 \\
\hline Performance IQ & $104.95 \pm 14.90$ & $109.72 \pm 15.59$ & $U=1017.5$ & 0.112 \\
\hline Gestational age & $29.48 \pm 1.98$ & -- & -- & -- \\
\hline Birthweight & $1311.12 \pm 376.41$ & -- & -- & -- \\
\hline Neonatal ultrasound (brain injury/normal) ${ }^{\mathrm{a}}$ & $28 / 36$ & -- & -- & -- \\
\hline Handedness $(L / R / A)^{b^{\wedge}}$ & $11 / 52 / 1$ & $1 / 28 / 0$ & $\begin{array}{l}\text { Fisher's exact } \\
=3.838\end{array}$ & 0.12 \\
\hline \multicolumn{5}{|l|}{ Socioeconomic status ${ }^{* a}$} \\
\hline I-II (professional and Intermediate) & 27 & 15 & Fisher's exact & 0.241 \\
\hline III (skilled manual and non-manual) & 26 & 15 & $=5.195$ & \\
\hline IV-V (semi-skilled and unskilled manual) & 2 & 0 & & \\
\hline Students & 1 & 4 & & \\
\hline Unemployed & 7 & 2 & & \\
\hline
\end{tabular}

$p$ values that remained significant after FDR correction are indicated in bold.

* Her Majesty's Stationary Office (1991), missing information for one participant.

a Neonatal brain injury includes uncomplicated periventricular hemorrhage without ventricular dilation and periventricular hemorrhage with ventricular dilation (Stewart et al., 1983).

${ }^{\text {b}}$ Fisher's exact test.

Missing information for seven control participants.

ments to evaluate whether (1) they would show the same pattern in very preterm born adults and controls, or (2) they would show different associations in the two participant groups.

\section{Materials and Methods}

Participants were part of a larger study that followed up a cohort of individuals born at $<33$ weeks of gestation who were admitted to the neonatal unit of University College Hospital, London, between 1979 and 1985. Term born control participants were recruited from the community and were matched in age to very preterm adults. Inclusion criteria were full-term birth (38-42 weeks), birth weight $>2500 \mathrm{~g}$, and age between 28 and 35 years. Exclusion criteria for the control group included birth complications (e.g., low birth weight defined as $<2500 \mathrm{~g}$, endotracheal mechanical ventilation), prolonged gestation (>42 weeks), severe hearing and motor impairments, and mental retardation indicated by intelligence quotient $(\mathrm{IQ})<70$. All study participants were native English speakers. Among these participants, 64 very preterm participants and 36 controls of either sex were assigned at random to complete a verbal fluency fMRI task.

IQ was assessed using the Wechsler Abbreviated Scale of Intelligence (WASI; Wechsler, 1999), which consists of four subtests that estimate verbal IQ, performance and full-scale IQ. Participants' handedness was assessed using the Modified Annett Questionnaire (Annett, 1967). The threshold used was which hand participants reported using in more than four out of six questions. Participants gave full informed consent and the study was approved by the appropriate local ethics committees, and in compliance with national legislation and the code of ethical principles for Medical Research Involving Human Subjects of the World Medical Association (Declaration of Helsinki).
Neonatal and socio-demographic information for all participants is shown in Table 1. Very preterm adults were slightly older and had lower verbal IQ scores than controls. Hence age was accounted for in all further analyses. Verbal IQ was not controlled for as it was assumed to share variance with the effect of interest. Performance IQ was not significantly different between the groups. There were no significant between-group differences in sex, socioeconomic status (Her Majesty's Stationary Office, 1991), or handedness.

\section{Phonemic verbal fluency task}

The fMRI task used in this study was a well-validated phonemic verbal fluency paradigm (Fu et al., 2002). Participants were required to overtly generate a word starting with the letter presented on a computer screen projected into the MRI scanner, but to not use proper names, grammatical variation of the previous word, or to repeat previous responses. If participants were unable to generate a response, they were asked to say "pass." Each letter was presented seven times within each block for a total of ten blocks, each block lasted $28 \mathrm{~s}$ (Fig. 1). The "easy" letters were: T, C, B, P, S; and the "hard" letters were: I, N, F, E, $G$. The categorization of easy and hard letters was based on the mean number of erroneous responses generated for each letter in a previous study (Fu et al., 2002). A 2 s "silent" period was set to allow for the participant to respond, coupled with a $2 \mathrm{~s}$ image volume acquisition period. During the "rest" blocks, participants were presented with the word rest and required to say rest out loud. The rest blocks were of the same duration as the task blocks. Verbal responses were recorded through an MRI-compatible microphone on Cool Edit 2000 (Syntrillium Software Corporation). Verbal fluency performance was assessed by the accuracy rate of participants' response (i.e., correctly producing a word starting with the 


\section{fMRI task paradigm}

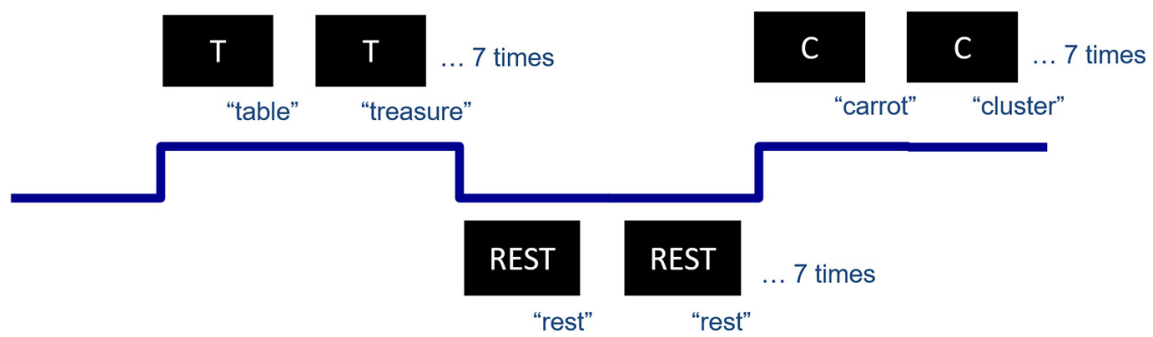

Figure 1. Verbal fluency fMRI task paradigm.

indicated letter; not using proper names, grammatical variation of the previous word, or saying pass). Participants were familiarized with the task before the fMRI experiment in an offline training session in which they were asked to make responses to example trials using a different set of letters.

\section{Image acquisition}

Data were collected using a GE 3 tesla Signa MR scanner (GE Healthcare). A gradient-echo EPI sequence (TR/TE $=2000 / 30 \mathrm{~ms}$ ) was used to collect data from 36 non-contiguous slices of $3.5 \mathrm{~mm}$ thickness separated by a distance of $0.5 \mathrm{~mm}$, and with in-plane voxel resolution of $3.75 \times 3.75 \mathrm{~mm}^{2}$. These were co-registered with T1weighted anatomic image (TR/TE/TI: 7.1/2.8/450 ms, matrix: $256 \times 256$ ), allowing for 196 slices with no gap and an isotropic resolution of $1.1 \times 1.1 \times 1.1 \mathrm{~mm}^{3}$.

Diffusion-weighted images were acquired using a multislice spin echo EPI sequence (TE $=104.5 \mathrm{~ms}$ ), obtaining 60 contiguous near-axial slice locations with isotropic (2.4 $\times 2.4 \times 2.4 \mathrm{~mm}^{3}$ ) voxels. The b value was $1300 \mathrm{~s} / \mathrm{mm}^{2}$, with 32 diffusion-weighted directions and four nondiffusion-weighted volumes. Peripheral cardiac gating was applied with an effective TR of 20/30 RR interval.

\section{fMRI analysis}

Statistical analysis of $\mathrm{fMRl}$ data was performed using FEAT from FSL (FMRIB Software Library; http://www. fmrib.ox.ac.uk/fsl). The three initial volumes were removed to minimize the effects of magnetic saturation. Pre-processing steps included motion correction (FSL's FLIRT), time-slice correction, spatial smoothing (Gaussian, FWHM $5 \mathrm{~mm}$ ), and temporal high-pass filtering (sigma $=50 \mathrm{~s}$ ). There were no statistically significant differences between very preterm and control participants in head motion during the fMRI task $(U=1111, p=0.59)$. Denoising was performed using FSL's independent component analysis ICA-based Xnoiseifier (FIX; Griffanti et al., 2014; Salimi-Khorshidi et al., 2014). The components of 20 participants (10 very preterms and 10 controls) were identified manually as noise or non-noise components according to established guidelines (Kelly et al., 2010). This information was used to train a classifier that can automatically classify the ICA components of each participant into noise or non-noise components. The time courses of the noise components were regressed out of the data. Regressors for each condition in the general linear model were convolved with a gamma hemodynamic response function. Only correct responses were used for the analyses. Individual participant data were then entered into a higher-level analysis using a mixed effects design (FLAME) whole-brain analysis and age was added as a covariate.

Three contrasts were studied: Easy $>$ Rest, Hard $>$ Rest, and Hard $>$ Easy. Cluster-based thresholding was used to find significant clusters. Z-statistic maps were thresholded at $z=2.3$. Voxels that pass the threshold formed clusters, and the spatial extent of each cluster was calculated. Then, random field theory was used to find the $p$ value of obtaining a cluster of a spatial extent given the chosen $z$-threshold and the spatial smoothness of the noise in the data under the null hypothesis. These $p$ values were corrected for family wise error across voxels and a threshold of $p<0.05$ was used to obtain significant clusters. From the resulting cluster maps, we identified clusters of hemodynamic response that significantly differed between groups, after controlling for participants' age. No significant results were found when comparing very preterm adults with brain injury, very preterm adults with normal ultrasound classification (subgrouped according to neonatal ultrasound [Stewart et al., 1983]) and controls; therefore, we focused on comparisons between all very preterm individuals and controls. In addition to exploring between-group differences in hemodynamic response, we also investigated whether hemodynamic response in brain areas displaying significant between-group differences was associated with on-line task performance and white matter tract characteristics. This was done by obtaining cluster masks of regions displaying significant between-group differences in hemodynamic response and extracting the parameter estimates of each individual.

\section{Normalization}

Each individual's functional data were registered to their structural scan using FSL's FLIRT (Jenkinson and Smith, 2001; Jenkinson et al., 2002) and boundary-based registration (BBR) cost function (Greve and Fischl, 2009). This technique extracts the surfaces from the T1weighted image, and then aligns the fMRI data to the T1-weighted data by maximizing the intensity gradient across tissue boundaries. This method has been shown to be more accurate and robust to signal inhomogeneities than traditional intrasubject registration algorithms. To map each individual's data into a common space, we used FSL-FNIRT (Andersson et al., 2010) to normalize 
each individual's structural data to a study-specific template, which is an average of 78 brain images from termborn and very preterm individuals as used in FroudistWalsh et al. (2015; available on request).

\section{Tractography analysis}

Preprocessing of diffusion MRI data followed the pipeline developed by Froudist-Walsh et al. (2015). Brain extraction was performed on the diffusion-weighted and b0 images using FSL's BET. Motion and eddy-current corrections were done on the brain-extracted data using ExploreDTI (Leemans et al., 2009). This motion correction step realigns the images and reorients the B-matrix so that the correct orientational information is preserved (Leemans and Jones, 2009). There were no statistically significant differences between very preterm and control participants in head motion in the diffusion data $(U=$ 1044, $p=0.84$ ). A constrained spherical deconvolution approach was chosen to differentiate multiple directions within one voxel (Tournier et al., 2004). We chose this approach as tractography using constrained spherical deconvolution outperforms tractography using other reconstruction methods when using data acquired with clinical b values (Wilkins et al., 2015). Constrained spherical deconvolution was performed using a damped version of the Richardson-Lucy algorithm (Dell'acqua et al., 2010). Parameters were chosen based on recommendations from the StarTrack manual (https://www.mr-startrack $. \mathrm{com} /$ ) and by visual inspection of the reconstruction to find the best possible balance between resolving multiple fiber orientations and minimizing false-positive fiber orientation distributions (FODs). The parameters used were: regularization threshold $\eta=0.02$, fiber response function $\alpha=2$, algorithm iterations $=300$, and regularization parameter $\mathrm{v}=20$; which is what was used in previous studies in the same cohort (Froudist-Walsh et al., 2015; Karolis et al., 2016; Tseng et al., 2017).

Visual inspection was performed in regions with known crossing fibers (e.g., between the corpus callosum, superior longitudinal fasciculus, and corticospinal tract) and without (e.g., middle of the corpus callosum).

Fiber orientation estimates were taken from the orientation of the peaks of the FOD profile. We used an absolute (equal to four times the amplitude of a spherical FOD obtained from a gray matter voxel) and a relative threshold (equal to $7 \%$ of the amplitude of the maximum amplitude of the FOD at that voxel) at each voxel to remove the general noise floor and surviving noise local maxima, respectively. Each FOD that survived the threshold were used as seeds to perform whole-brain tractography. Fiber orientation streamlines were propagated using Euler integration with a step size of $1 \mathrm{~mm}$. Propagation stopped if the angle between two successive steps exceeded $60^{\circ}$. As the AF is a curved bundle, a more lenient angular threshold was used to ensure the AF could be reconstructed in all participants. This threshold is also close to that used by Phillips et al. $\left(55^{\circ}\right)$ to preclude the generation of fibers with biologically unrealistic curvature (i.e., "looping" fibers; Phillips et al., 2012). Tractography reconstruction was performed using StarTrack (Dell'Acqua et al.,

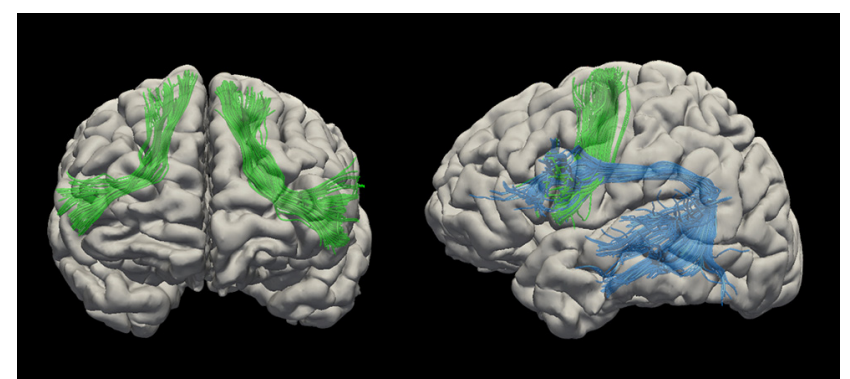

Figure 2. The arcuate fasciculus (blue) and frontal aslant tract (green).

2013). The final reconstructed whole-brain tractography was visually assessed for all participants.

White matter dissection of the AF and FAT were performed in native diffusion space in TrackVis (http:// www.trackvis.org) using a two-region method (Catani and Thiebaut de Schotten, 2008; Catani et al., 2012). In this study, we only considered the long segment of the AF, which is the only bundle that arches around the Sylvian fissure to connect posterior temporal regions to the IFG. The AF was identified using regions of interest $(\mathrm{ROI})$ of the IFG and posterior STG and middle temporal gyrus (MTG). Tracts that passed through these ROls, but originated from the anterior temporal regions, were excluded in order not to include the middle longitudinal temporal parietal tracts. The FAT was identified using ROls of the IFG (defined as BA45 and 44) and posterior superior frontal gyrus. All ROls were hand drawn for each participant and all tracts were dissected in both hemispheres. Artefactual/ non-anatomic fibers were removed using manually drawn region-of-avoidances based on the literature of brain anatomy and shape of the tract (Catani et al., 2012; Dick and Tremblay, 2012). An example of the dissected tracts is shown in Figure 2. White matter tracts were evaluated by HMOA and volume. White matter tract volumes were adjusted for intracranial volume by dividing tract volume by intracranial volume. Age was controlled for in all white matter variables using robust regression and a logistic weight function in MATLAB (MATLAB and Statistics Toolbox Release R2014b, The MathWorks, Inc.), the residuals were then used for further statistical analysis described below.

\section{Lateralization}

Laterality index (LI) of the white matter tract measures $\left(\mathrm{HMOA}\right.$, volume, FA, RD) were obtained by $\mathrm{LI}=\left(\mathrm{Q}_{\mathrm{left}}{ }^{-}\right.$ $\mathrm{Q}_{\text {right }} /\left(\mathrm{Q}_{\text {left }}+\mathrm{Q}_{\text {right }}\right)($ Seghier, 2008).

\section{Statistical analysis of demographic, behavioral, and IQ data and integration of imaging-derived measures}

Statistical analyses were done in SPSS 21 (IBM SPSS Statistics for Macintosh, version 21.0). The distributions of the imaging (fMRI and white matter tract measurements: left and right $A F$ HMOA and volume, left and right FAT HMOA and volume, and LI of AF and FAT HMOA and volume), demographic (age, gestational age, birth weight), behavioral (verbal fluency task performance, head motion), and verbal and performance IQ data were tested for 
Table 2. Participants' on-line verbal fluency performance

\begin{tabular}{lllr}
\hline & Very preterm & Control & Test statistic \\
Task performance & Accuracy (mean \pm SD) & & $U=1449.5$ \\
Easy letters & $0.83 \pm 0.15$ & $0.89 \pm 0.10$ & $U=1647.0$ \\
Hard letters & $0.70 \pm 0.17$ & $0.83 \pm 0.13$ & 0.032 \\
Correct response time & Milliseconds (mean \pm SD) & & $<.001$ \\
Easy letters & $660.04 \pm 159.11$ & $640.83 \pm 197.53$ & $U=875.0$ \\
Hard letters & $636.73 \pm 156.34$ & $610.17 \pm 180.78$ & $U=905.0$ \\
\hline
\end{tabular}

$p$ values that remained significant after FDR correction are indicated in bold.

normality using a Shapiro-Wilk test. Not all variables were normally distributed; therefore, group comparisons were performed using Mann-Whitney $U$ tests and correlation tests were performed using Spearman's correlation. To explore possible between-group differences in the associations between $\mathrm{fMRI}$ data and task performance and white matter tract measurements, all analyses were performed first across the whole sample, then within each group (control and very preterm). After identifying significant within-group associations, interaction terms were included in a univariate linear regression analysis to test for between groups differences in such associations. Multiple comparison correction was performed using false discovery rate (FDR; Benjamini and Hochberg, 1995). to investigate whether verbal fluency performance was driven by between-group differences in verbal IQ, additional analyses were performed to evaluate the relationship between verbal fluency and verbal IQ.

\section{Results}

\section{Verbal fluency performance}

Very preterm adults performed significantly worse than controls on the hard letter trials $(U=1449.5, p<0.001)$ but not the easy letter trials of the on-line verbal fluency task $(U=1647.0, p=0.032$, non-significant after FDR correction). There were no statistically significant group differences in correct response times for both easy and hard letters (Table 2).

\section{fMRI analysis}

Group main effect on the Easy $>$ Rest condition showed positive hemodynamic responses in bilateral paracingulate gyrus, superior, middle, inferior frontal gyrus, anterior insula, caudate, intracalcarine cortex, cerebellum, left precentral gyrus, superior parietal lobule, supramarginal gyrus, putamen, thalamus, middle and inferior temporal gyrus, and lateral occipital cortex (LOC) in both very preterm adults and controls. Very preterm adults also showed positive hemodynamic responses in right precentral gyrus, putamen, and thalamus. The Hard $>$ Rest condition showed similar patterns of positive hemodynamic responses with additional involvement of bilateral STG and right supramarginal gyrus and inferior temporal gyrus. When looking at group main effect on the Hard > Easy condition, the control group showed positive hemodynamic responses in the left LOC.

The very preterm group did not show any regions displaying positive hemodynamic response (Table 3; Fig. 3).

Group main effect on the Easy $>$ Rest condition showed hemodynamic response suppression (i.e., a less negative hemodynamic response) in bilateral precuneus/ posterior cingulate cortex (PCC), inferior parietal lobule, occipital fusiform, lingual, superior and middle temporal gyri, insula, lateral occipital, sensorimotor, anterior cingulate cortices, superior frontal gyrus, thalamus, hippocampus, parahippocampus, amygdala, right putamen, and left cerebellum in both very preterm and control participants. Control participants also showed hemodynamic response suppression in the right frontal pole, while very preterm adults showed hemodynamic suppression in the left putamen. Group main effect on the Hard > Rest condition showed hemodynamic response suppression in similar regions as well as the right cerebellum. Very preterm adults had increased suppression in the left middle frontal gyrus. On the Hard $>$ Easy condition, the control group showed no regions of hemodynamic response suppression. The very preterm group showed hemodynamic response suppression in bilateral precuneus, left PCC and LOC (Table 3; Fig. 3).

When comparing the hemodynamic responses between groups, very preterm participants showed decreased hemodynamic response suppression in both the Easy $>$ Rest and Hard > Rest conditions compared to controls. In the Easy > Rest condition, this was observed in a region that extended from the right STG to the posterior insula and thalamus. In the Hard $>$ Rest condition, very preterm participants showed decreased negative hemodynamic response compared to controls in the left and right STG (also extending to the insula) as well as the right sensorimotor cortex. In the Hard > Easy condition, very preterm adults showed greater hemodynamic response suppression compared to controls in bilateral LOC (Table 4; Fig. 4).

The regions which displayed between-group differences in hemodynamic responses were also those that showed negative hemodynamic responses in both groups, with the exception of the thalamus, where positive hemodynamic response was found in the very preterm group. The hemodynamic responses in these regions ranges across negative and positive values in very preterm adults (Table 4).

\section{Tractography analysis}

The AF and FAT did not differ between groups in terms of volume or HMOA in either hemisphere, nor did they differ in terms of LI.

\section{Functional-behavioral associations}

The contrast of parameter estimates in regions where between-group differences in hemodynamic response 
Table 3. Hemodynamic responses in very preterm adults and controls during easy and hard letter trials

\begin{tabular}{|c|c|c|c|c|}
\hline Condition & & Region & $\begin{array}{l}\text { Peak MNI } \\
\text { coordinate } \\
{[x, y, z](\mathrm{mm})^{\mathrm{a}}}\end{array}$ & $\begin{array}{l}\text { Cluster } \\
\text { size (voxels) }\end{array}$ \\
\hline \multirow[t]{6}{*}{$\begin{array}{l}\text { Control } \\
\text { Easy }>\text { Rest }\end{array}$} & $\begin{array}{l}\text { Positive hemodynamic } \\
\text { response }\end{array}$ & $\begin{array}{l}\text { Bilateral paracingulate gyrus, SFG, MFG, IFG, anterior insula, caudate, intracalcarine } \\
\text { cortex, cerebellum; left precentral gyrus, putamen, thalamus }\end{array}$ & $\begin{array}{c}{[-50,10,30]} \\
{[36,10,32]} \\
{[-6,10,60]} \\
{[-4,16,46]} \\
{[8,30,34]} \\
{[-42,2,26]}\end{array}$ & 114,161 \\
\hline & & Left SPL, SMg, LOC & {$[-48,-38,40]$} & 8772 \\
\hline & & Left STG, ITG & {$[-48,-50,-10]$} & 3073 \\
\hline & $\begin{array}{l}\text { Negative hemodynamic } \\
\text { response }\end{array}$ & $\begin{array}{l}\text { Bilateral precuneus/PCC, IPL, insula, LOC, sensorimotor cortex, ACC, SFG, thalamus, } \\
\text { occipital fusiform gyrus, lingual gyrus, hippocampus, parahippocampus, } \\
\text { amygdala; right frontal pole, MTG }\end{array}$ & $\begin{array}{c}{[-1,-49,27]} \\
{[7,-53,27]} \\
{[6,-65,28]} \\
{[52,-56,28]} \\
{[57,-60,28]} \\
{[-55,-60,33]}\end{array}$ & 257,987 \\
\hline & & Left cerebellum & {$[-27,-40,-52]$} & 2701 \\
\hline & & Left MTG & {$[-52,3,-15]$} & 2690 \\
\hline \multirow[t]{8}{*}{$\begin{array}{l}\text { Very preterm } \\
\text { Easy }>\text { Rest }\end{array}$} & $\begin{array}{l}\text { Positive hemodynamic } \\
\text { response }\end{array}$ & $\begin{array}{l}\text { Bilateral paracingulate gyrus, SFG, MFG, IFG, precentral gyrus, anterior insula, } \\
\text { caudate, putamen, thalamus, intracalcarine cortex, cerebellum; } \\
\text { left STG, ITG }\end{array}$ & $\begin{array}{l}{[-8,18,40]} \\
{[2,20,46]} \\
{[-46,2,26]} \\
{[-52,2,22]} \\
{[-6,14,52]} \\
{[-4,18,48]}\end{array}$ & 188,520 \\
\hline & & Left SPL, SMg, LOC & {$[-30,-68,46]$} & 12146 \\
\hline & Negative hemodynamic & Right PCC, precuneus, sensorimotor cortex & {$[4,-50,30]$} & 79420 \\
\hline & response & Right LOC, SMg, AG, insula, MTG, putamen, thalamus & {$[49,-68,34]$} & 76944 \\
\hline & & Left LOC, SMg, AG, insula, MTG & {$[-54,-62,34]$} & 46079 \\
\hline & & Bilateral ACC, SFG & {$[-2,52,2]$} & 30281 \\
\hline & & Left occipital fusiform gyrus, lingual gyrus, parahippocampus, thalamus & {$[-14,-88,-12]$} & 8467 \\
\hline & & Left cerebellum & {$[-24,-75,-35]$} & 1815 \\
\hline \multirow[t]{13}{*}{$\begin{array}{l}\text { Control } \\
\text { Hard }>\text { Rest }\end{array}$} & $\begin{array}{l}\text { Positive hemodynamic } \\
\text { response }\end{array}$ & $\begin{array}{l}\text { Bilateral paracingulate gyrus, SFG, MFG, IFG, precentral gyrus, anterior insula, } \\
\text { caudate, putamen, intracalcarine cortex, cerebellum }\end{array}$ & $\begin{array}{c}{[-50,6,32]} \\
\quad[-50,14,28] \\
\quad[-44,24,18] \\
\quad[-6,12,56] \\
\quad[-2,16,46]\end{array}$ & 125,306 \\
\hline & & Left SPL, SMg, LOC & {$[-46,-40,38]$} & 13,728 \\
\hline & & Left ITG & {$[-40,-60,-8]$} & 4259 \\
\hline & & Right MFG & {$[40,40,36]$} & 2731 \\
\hline & $\begin{array}{l}\text { Negative hemodynamic } \\
\text { response }\end{array}$ & $\begin{array}{l}\text { Bilateral PCC, precuneus, sensorimotor cortex; right LOC, SMg, AG, insula, MTG, } \\
\text { hippocampus, parahippocampus, amygdala, occipital fusiform gyrus, } \\
\text { lingual gyrus, putamen, thalamus }\end{array}$ & $\begin{array}{l}{[10,-56,28]} \\
{[48,-60,28]} \\
{[48,-53,20]} \\
{[48,-60,38]} \\
{[52,-56,32]}\end{array}$ & 164,196 \\
\hline & & Bilateral ACC, SFG; right MFG & {$[4,44,4]$} & 33,368 \\
\hline & & Left LOC, SMg, AG, & {$[-52,-61,32]$} & 15,964 \\
\hline & & Left insula & {$[-38,-20,20]$} & 15,701 \\
\hline & & $\begin{array}{l}\text { Left cerebellum, occipital } \\
\text { fusiform gyrus }\end{array}$ & {$[-30,-74,-36]$} & 9585 \\
\hline & & Left MTG & {$[-57,0,-26]$} & 6999 \\
\hline & & Bilateral cerebellum & {$[6,-38,-52]$} & 4063 \\
\hline & & Left thalamus & {$[-15,-26,3]$} & 2301 \\
\hline & & Right frontal pole & {$[44,42,-15]$} & 1818 \\
\hline \multirow[t]{6}{*}{$\begin{array}{l}\text { Very preterm } \\
\text { Hard }>\text { Rest }\end{array}$} & $\begin{array}{l}\text { Positive hemodynamic } \\
\text { response }\end{array}$ & $\begin{array}{l}\text { Bilateral paracingulate gyrus, SFG, MFG, IFG, precentral gyrus, anterior insula, } \\
\text { caudate, putamen, intracalcarine cortex, STG, ITG, cerebellum; } \\
\text { left SPL, SMg, LOC }\end{array}$ & $\begin{array}{c}{[-6,12,52]} \\
{[-42,4,28]} \\
{[-8,22,40]} \\
{[-6,18,48]} \\
{[2,18,48]}\end{array}$ & 215,947 \\
\hline & & Right SMg & {$[50,-34,48]$} & 2236 \\
\hline & $\begin{array}{l}\text { Negative hemodynamic } \\
\text { response }\end{array}$ & $\begin{array}{l}\text { Bilateral PCC, precuneus, sensorimotor cortex; right frontal pole, LOC, SMg, AG, } \\
\text { insula, MTG, occipital fusiform gyrus, lingual gyrus, parahippocampus, } \\
\text { hippocampus, amygdala, putamen, thalamus }\end{array}$ & $\begin{array}{c}{[12,-62,28]} \\
\quad[8,-64,28] \\
{[8,-52,29]} \\
{[-10,-50,39]} \\
{[-5,-48,38]}\end{array}$ & 144,407 \\
\hline & & $\begin{array}{l}\text { Left LOC, SMg, AG, insula, MTG, occipital fusiform gyrus, lingual gyrus, } \\
\text { parahippocampus, hippocampus, amygdala, putamen, thalamus }\end{array}$ & {$[-49,-59,38]$} & 53,775 \\
\hline & & Bilateral ACC, SFG, MFG & {$[-5,52,18]$} & 36,855 \\
\hline & & Bilateral cerebellum & {$[-9,-46,-46]$} & 2930 \\
\hline
\end{tabular}

a Sub-peaks are only reported for clusters larger than 100,000 voxels.

*All clusters were obtained with $z=2.3, p<0.05$ (corrected for family wise error across voxels).

$\mathrm{SFG}=$ superior frontal gyrus; MFG = middle frontal gyrus; IFG = inferior frontal gyrus; $\mathrm{SPL}=$ superior parietal lobule; $\mathrm{SMg}=$ supramarginal gyrus; AG = angular gyrus; PCC = posterior cingulate cortex; MTG = middle temporal gyrus; ITG = inferior temporal gyrus, LOC = lateral occipital cortex. 


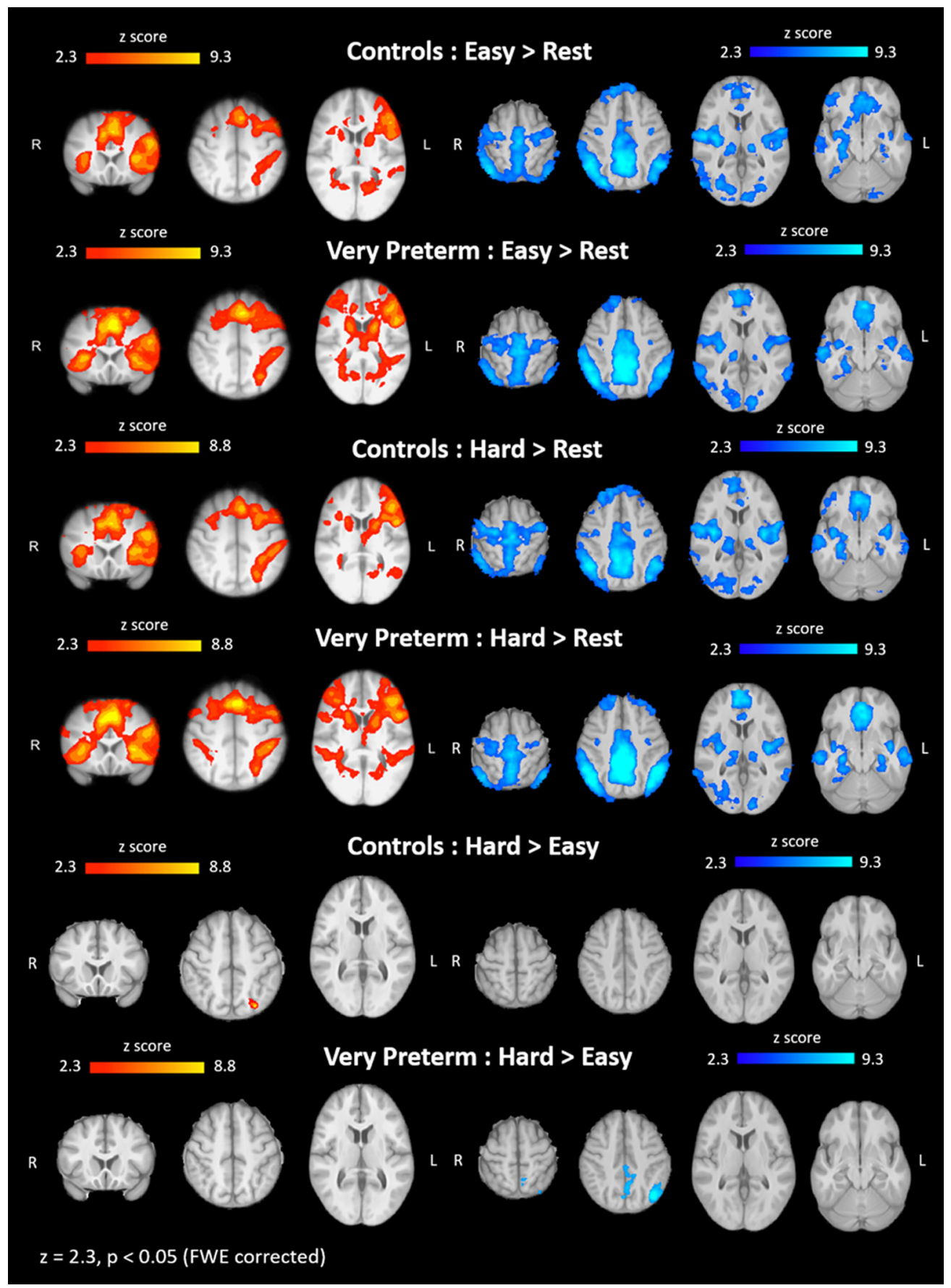

Figure 3. Hemodynamic responses in very preterm adults and controls during easy and hard letter trials. Positive hemodynamic response clusters are shown in red-yellow, negative hemodynamic response clusters are shown in blue-light blue. FWE = family wise error.

where found (Easy > Rest: right STG; Hard > Rest: left STG, right STG, and right sensorimotor cortex, Hard > Easy: left and right LOC) was correlated with participants' online task performance and head motion.

Only increased hemodynamic response in the right sensorimotor cortex in the Hard > Rest condition in the whole sample was significantly negatively correlated with performance on the hard letter trials of the on-line verbal fluency task $(r=-0.284, p=0.004)$, i.e., the greater the hemodynamic response the worse the performance (Fig. 5). All the correlation tests were corrected for multiple comparisons. Within-group analyses did not reveal any significant group-specific association between hemodynamic response and verbal fluency performance. Head motion during the $\mathrm{fMRI}$ task was not associated with any of the $\mathrm{fMRl}$ findings.

\section{Structural-behavioral associations}

As no significant between-group differences in white matter tract indices were observed, associations between white matter tract indices and behavior were not further explored. 
Table 4. Differences in hemodynamic responses between very preterm adults and controls during easy and hard letter trials

\begin{tabular}{|c|c|c|c|c|c|}
\hline $\begin{array}{l}\text { Condition } \\
\text { Easy }>\text { Rest }\end{array}$ & Region & $\begin{array}{l}\text { Peak MNI coordinate } \\
{[x, y, z](\mathrm{mm})}\end{array}$ & $\begin{array}{l}\text { Cluster size } \\
\text { (voxels) }\end{array}$ & $p$ value* & $\begin{array}{l}\text { Contrast of } \\
\text { parameter estimate } \\
\text { (mean } \pm \text { SD) } \\
\text { (very preterm; control) }\end{array}$ \\
\hline Very preterm $>$ control & Right STG, insula, thalamus & {$[68,-2,4]$} & 3838 & $<0.001$ & $-2.65 \pm 11.71 ;-12.39 \pm 11.21$ \\
\hline \multicolumn{6}{|l|}{ Hard $>$ Rest } \\
\hline Very preterm > control & $\begin{array}{l}\text { Right STG, insula } \\
\text { Left STG, insula } \\
\text { Right sensorimotor cortex }\end{array}$ & $\begin{array}{l}{[62,-18,-6]} \\
{[-54,-4,2]} \\
{[48,-40,68]}\end{array}$ & $\begin{array}{l}8492 \\
2079 \\
2013\end{array}$ & $\begin{array}{l}<0.001 \\
0.02 \\
0.02\end{array}$ & $\begin{array}{l}0.02 \pm 10.12 ;-11.56 \pm 10.27 \\
-3.52 \pm 13.56 ;-15.34 \pm 10.86 \\
-1.54 \pm 14.16 ;-12.71 \pm 13.99\end{array}$ \\
\hline Hard $>$ Easy & & & & & \\
\hline Very preterm $<$ control & $\begin{array}{l}\text { Left LOC } \\
\text { Right LOC }\end{array}$ & $\begin{array}{l}{[-30,-76,45]} \\
{[43,-82,30]}\end{array}$ & $\begin{array}{l}2356 \\
1944\end{array}$ & $\begin{array}{l}0.00567 \\
0.0185\end{array}$ & $\begin{array}{l}-3.01 \pm 19.21 ; 9.84 \pm 16.43 \\
-2.33 \pm 26.59 ; 6.34 \pm 12.06\end{array}$ \\
\hline
\end{tabular}

${ }^{*}$ Cluster $p$ values were obtained with $z=2.3, p<0.05$ (corrected for family wise error rate across voxels).

$\mathrm{STG}=$ superior temporal gyrus; LOC = lateral occipital cortex.

\section{Functional-structural associations}

Correlation tests across the whole sample did not show any significant functional-structural associations. Withingroup analyses revealed group-specific patterns of association between hemodynamic response and white matter characteristics. Hemodynamic response in right sensorimotor cortex in the Hard > Rest condition significantly negatively correlated with the laterality of AF HMOA in controls $(r=-0.419, p=0.011)$, but not in very preterm individuals $(r=0.003, p=0.981)$, i.e., the more hemodynamic response suppression the more left-lateralized the AF HMOA. This association was significantly different between groups (lateralization $\times$ group interaction: $F=$ 7.446, $p=0.008$; Fig. 6A). Hemodynamic response in the right STG in the Easy $>$ Rest condition also significantly negatively correlated with AF HMOA laterality in controls ( $r$ $=-0.405, p=0.014$ ), but not in very preterm individuals $(r=0.14, p=0.269)$, and this significantly differed between groups (lateralization $\times$ group interaction: $F=$ $5.494, p=0.021$; Fig. 6B). Hemodynamic response in the left STG in the Hard > Rest condition negatively correlated with the left FAT volume in the very preterm group and not in the control group, but this association was not significantly different between groups (volume $\times$ group interaction: $F=3.326, p=0.071$ ). All the correlation tests were corrected for multiple comparison correction.

\section{Analyses including only right-handed participants}

As handedness may be associated with laterality (Knecht et al., 2000), all analyses were repeated for righthanded participants only (very preterm adults $n=52$; controls $n=28$ ). In these analyses, all significant results reported above remained unaltered, except for the association between left STG hemodynamic response during the hard letter trials and the left FAT volume in the very preterm group, which was no longer significant.

However, other significant structure-function associations became evident: in the very preterm group, but not in controls, higher left and right FAT HMOA were associated with increased right STG hemodynamic response suppression during hard letter trials $(r=-0.411, p=$ $0.002 ; r=-0.315, p=0.023$ ). The association of the left FAT HMOA and right STG hemodynamic response was significantly different between groups (lateralization $x$ group interaction: $F=4.44, p=0.038$ ).

\section{Association between verbal fluency and verbal IQ}

In the whole sample, verbal IQ was significantly associated with verbal fluency performance on the easy and hard letter trials $(r=0.321, p=0.002 ; r=0.413, p<$ $0.001)$. Within-group analyses showed that verbal IQ was only significantly associated with verbal fluency on hard letter trials in very preterm adults $(r=0.42, p=0.001)$ but not in controls $(r=0.296, p=0.113)$. However, the difference between the correlation coefficients in the two groups was not statistically significant.

\section{Sex differences within the very preterm group}

Very preterm males performed better than very preterm females on the easy letter trials $(U=301.0, p=0.015)$; no sex difference was found on the hard letter trials $(U=$ 389.0, $p=0.235$ ). Very preterm males also had higher verbal IQ and performance IQ than very preterm females (verbal IQ: $U=214.5, p=0.003$, performance IQ: $U=$ $239.0, p=0.014)$. There was however no evidence of sex differences in regions where group differences in hemodynamic response were observed during verbal fluency processing.

\section{Discussion}

This study investigated the functional and structural brain correlates of verbal fluency in adulthood following very preterm birth. At a functional level, results showed decreased hemodynamic response suppression in very preterm adults compared to controls in several brain regions, which seemed to be suboptimal for completion of hard letter verbal fluency trials. At a structural level, increased left-laterality in the AF was associated with increased right hemispheric functional deactivation in controls but not in very preterm adults. These findings suggest that alterations in the typical development of left-lateralization in very preterm individuals are still present in adulthood.

\section{fMRI results and verbal fluency performance}

Very preterm adults compared to controls showed decreased hemodynamic response suppression in the right 


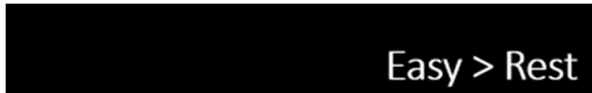

Very Preterm > Control

R

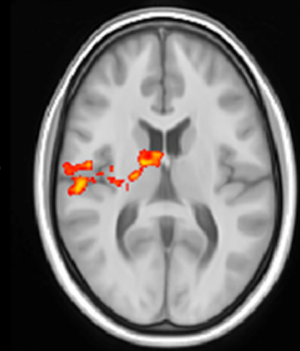

L P

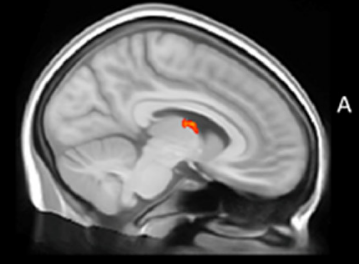

Hard > Rest

Very Preterm > Control

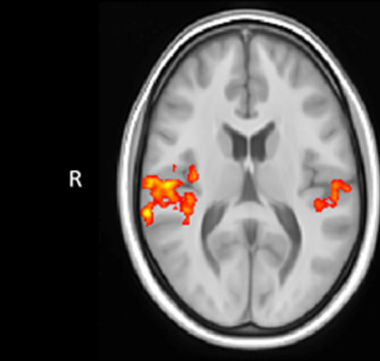

L

F
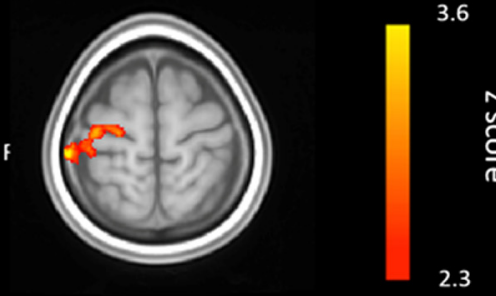

Hard > Easy

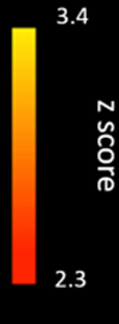

R

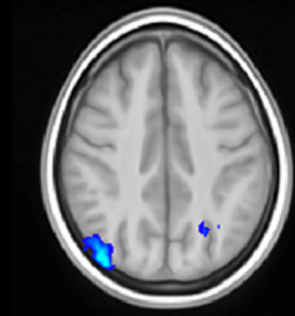

L

R

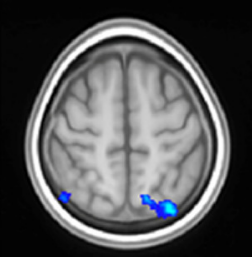

3.6

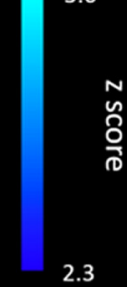

$\mathrm{z}=2.3, \mathrm{p}<0.05$ (FWE corrected)

Figure 4. Differences in hemodynamic response between very preterm adults and controls during Easy $>$ Rest, Hard $>$ Rest, and Hard $>$ Easy conditions. Red-yellow indicates relatively increased hemodynamic response in the very preterm group compared to controls, while blue indicates relatively decreased hemodynamic response in the very preterm group compared to controls. $\mathrm{FWE}=$ family wise error.

STG, posterior insula and thalamus during completion of both easy and hard letters of a verbal fluency task. During processing of hard letters, altered hemodynamic responses in the very preterm group were more extensive and included left STG and insula and right sensorimotor cortex. Hemodynamic responses in these regions showed a more dynamic range of both positive and negative measures in very preterm adults. This could reflect individual differences when performing verbal fluency, with some participants engaging regions that are not typically required for the specific tasks or some participants failing to suppress a region. Taken together with the findings that very preterm adults performed worse on the hard letters but not the easy letters compared to term-born controls, these results suggest that hemodynamic responses are particularly affected when a task presents high-cognitive demands. In the following paragraphs we will discuss findings with regards to each region.

The STG has been recognized to play a role in speech recognition and comprehension. The left and right hemisphere, however, process speech differently. Hickok and Poeppel (2007) proposed that integration of information 


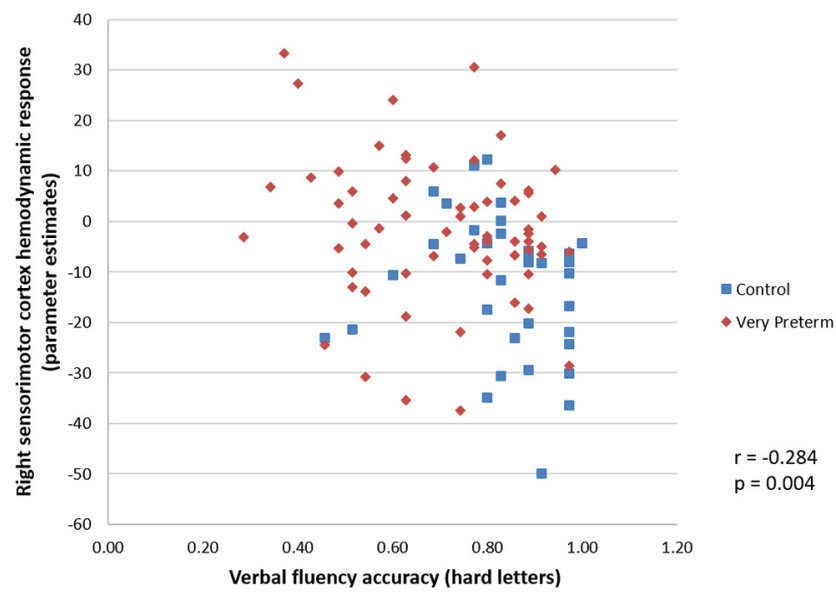

Figure 5. Verbal fluency accuracy and right sensorimotor cortex hemodynamic response during hard letter trials in the whole sample.

over longer timescales predominantly occurs in the right hemisphere, while integration over shorter timescales may be more bilateral. Another view is that the left hemisphere may be associated with phonemic perception and process information more categorically than the right hemisphere (Liebenthal et al., 2005). Other than differ-

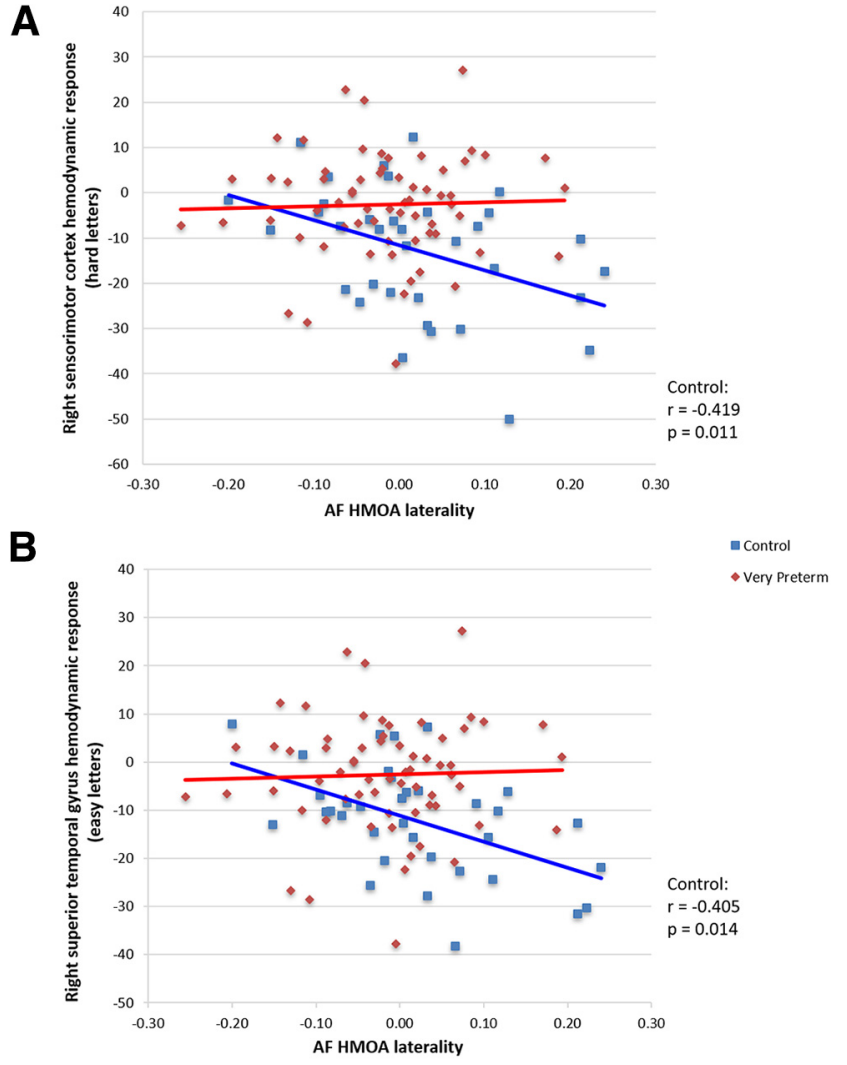

Figure 6. Associations between hemodynamic response and white matter characteristics in each group. $\boldsymbol{A}$, Right sensorimotor cortex hemodynamic response (hard letter trials) and AF HMOA laterality. B, Right STG hemodynamic response (easy letter trials) and $\mathrm{AF}$ HMOA laterality. $\mathrm{AF}=$ arcuate fasciculus, $\mathrm{HMOA}=$ hindrance modulated orientational anisotropy. ences in speech processing, the left and right STG also differ in their involvement in speech production. Specifically, the left posterior STG is suggested to be involved in the phonological processing of both speech input and output (Hickok et al., 2003, 2009). In regards to verbal fluency, a previous PET study revealed a decrease in relative cerebral blood flow in bilateral STG during a letter verbal fluency task in controls (Frith et al., 1991). Similarly, decreased hemodynamic response was found in the right STG when comparing hemodynamic response during verbal fluency to an automatic speech control condition in healthy participants (Birn et al., 2010). These differences could be due to differences in auditory processing and STG suppression may be needed to perform the task.

The insula has a known role in language processing due to its strong connections to the IFG and temporal cortex. In particular, the posterior insula has been found to be involved in word retrieval and lexical knowledge (Ardila et al., 2014), which is utilized during verbal fluency tasks. Based on a model proposed by Just and Varma (2007), when a task is sufficiently difficult, resource demands on the typical brain network engaged by such task will exceed resource supplies, and additional brain regions with spare resources and relevant functional specializations will be recruited to aid task performance. When an individual's resource supply is reduced as a result of neurodevelopmental alterations, recruitment of additional brain regions to aid task performance may occur. It was previously shown that individuals born very preterm who sustained perinatal brain injury displayed increased hemodynamic response in bilateral insula and associated perisylvian areas, and this correlated with performance on a verbal working memory task (Froudist-Walsh et al., 2015). The insula is also involved in a wide range of other functions, such as auditory, motor, affective and gustatory processing (Chang et al., 2013). Very preterm adults may have showed decreased hemodynamic response suppression in the insula during completion of a verbal fluency task because they may have required the support of a wider range of cognitive functions than those employed by control participants. The "extra" recruitment of hemodynamic resources during language processing has been previously observed in preterm adolescents during performance of a sentence comprehension task (Barde et al., 2012).

Increased hemodynamic response in the very preterm compared to the control group was also found in the thalamus. The thalamus is activated during letter fluency in healthy controls (Ravnkilde et al., 2002), and thalamic lesions lead to impairment in verbal fluency (Annoni et al., 2003). The thalamus is vulnerable to very preterm birth and volumetric deficits are often described in very preterm individuals (Boardman et al., 2006; Nosarti et al., 2014). Volumetric reductions of the thalamic nuclei have been associated with worse letter verbal fluency in very preterm adolescents (Gimenez et al., 2006). The thalamus may represent a central monitor for language-related cortical activities, controlling and adapting the connectivity between cortical regions and bandwidth the exchange of information (Klostermann et al., 2013). The increased he- 
modynamic response in the thalamus we see in our results may indicate the increased effort very preterm adults need to complete a letter fluency task, although we only noticed this during the easy and not the hard letters. It is therefore possible that increased thalamic response is reflective of more effective information processing to facilitate task performance.

The sensorimotor cortex was the only region that showed decreased hemodynamic response suppression during completion of hard letter trials in the preterm group compared to controls that is not typically involved in language processing. The cortical systems for action control and language were traditionally thought to be independent systems, although more recent theoretical views suggest these may be served by interactive functional systems (Pulvermuller, 2005). Evidence of white matter connections between motor and language regions and somatotopic activation in the motor cortex in response to action-related words supports this notion (Pulvermuller, 2005; Pulvermuller and Fadiga, 2010). Schafer et al. (2009) found that in preterm adolescents, hemodynamic response in the left sensorimotor cortex during a lexical semantic association $\mathrm{fMRI}$ task was correlated with better task performance. In the same study, functional connectivity between typical language-related temporal and sensorimotor areas was only present in preterm adolescents, suggesting that the sensorimotor cortex may mediate connections between language areas in the preterm brain.

Using a verbal fluency task, we found that at the whole group level decreased hemodynamic response suppression in right sensorimotor cortex during completion of the hard letter trials was associated with participants' poorer task performance, supporting the idea that increased neural recruitment does not necessarily lead to better cognitive performance (Turkeltaub et al., 2012; Tseng et al., 2017). This finding may be expected given that significant group differences in verbal fluency (hard letters) and right sensorimotor cortex hemodynamic response were found. Nonetheless, other regions that also exhibited differences in hemodynamic response did not show an association with verbal fluency performance. Previous research suggested that recruitment of right hemispheric mechanisms for language may occur when left hemispheric specialization is disrupted, although it is unclear whether this leads to the successful acquisition of typical language skills (Holland et al., 2007). Contrasting findings between the current and Schafer's study could be due to the use of different tasks assessing different language processes.

Around half of all participants (and the majority of controls) had a negative contrast of parameter estimate in the right sensorimotor cortex, indicating that suppression of this region compared to the baseline is needed to perform well on a verbal fluency task. Intrasubject comparisons of fMRI deactivation during visual attention and working memory processing suggest that deactivation may be an inhibition mechanism to reduce distracting neural processes, rather than a local reduction of relative cerebral blood flow in less active brain regions due to increased relative cerebral blood flow in activated brain regions
(Tomasi et al., 2006). Better visual attention performance has in fact been associated with stronger disconnection of task-irrelevant brain regions (Tomasi et al., 2014).

Greater LOC hemodynamic response suppression in very preterm adults compared to controls in the Hard $>$ Easy condition could be related to differences in word form processing. The LOC is connected to the visual word form area through the vertical occipital fasciculus (Yeatman et al., 2013). Damage to the anterior vertical occipital fasciculus has been found to impair reading abilities (Yeatman et al., 2014). It is possible that this region is more engaged during the REST control condition when reading a word and dependent on successful word retrieval during the task conditions. However, white matter properties and task performance were not associated with this difference.

\section{Structural MRI results}

Contrary to our prediction, very preterm adults did not have smaller volume and $\mathrm{HMOA}$ and decreased-left lateralization in both structural indices of the AF and FAT compared to term-born controls. One possible explanation could be that the primary site of perinatal injury (i.e., periventricular hemorrhage) involves periventricular regions, therefore affecting subcortical regions and its connections (e.g., the dorsal and ventral cingulum and the fornix) to a greater extent than structures that lie more laterally in the brain (Froudist-Walsh et al., 2015). In previous studies, it was also shown that the superior longitudinal fasciculus, which is distant from the ventricles, did not exhibit between-group volumetric differences, suggesting that there may be a medial-lateral gradient of risk for structural injury following very preterm birth (FroudistWalsh et al., 2015; Caldinelli et al., 2017). A lack of significant group differences in AF and FAT, which connect to or within the frontal lobe, could be also interpreted using a neurodevelopmental perspective: the frontal lobe displays protracted maturation compared to other brain areas (Petanjek et al., 2011), possibly resulting in decreased vulnerability of its white matter connections to early brain insults.

\section{Functional-structural associations}

We expected that increased right hemispheric hemodynamic response in very preterm adults would be associated with increased right-lateralization of AF or FAT white matter indices. Instead, only in controls we found an association between increased right-lateralization of $\mathrm{AF}$ HMOA and decreased hemodynamic response suppression in right STG in the Easy $>$ Rest condition and in right sensorimotor cortex in the Hard $>$ Rest condition. As decreased hemodynamic response suppression in right sensorimotor cortex was associated with worse verbal fluency performance on hard letter trials, these findings highlight the importance of left-lateralization for languagerelated functions. Part of the left AF is considered as a direct phonologic pathway and may be particularly important to aid children's language acquisition (Glasser and Rilling, 2008), and early leftward AF asymmetry is seen in term-born infants (Dubois et al., 2009). The fact that this was not found in very preterm adults may indicate a 
lateralization alteration, considering that the asymmetry of the cerebral hemispheres (most prominently in perisylvian cortex) emerges during the late second and third trimester of gestation, when very preterm birth occurs (Habas et al., 2012).

Neuroimaging studies investigating language functions in preterm individuals have highlighted the importance of interhemispheric connections and lateralization in language development (Salvan and Nosarti, 2018). An increased right-hemispheric engagement found in this study has been previously reported during language tasks in preterm individuals (Gozzo et al., 2009; Myers et al., 2010; Scheinost et al., 2015) and may reflect deviations in typical cortical language network development, when functional specialization increases (Skeide and Friederici, 2016). Atypical lateralization of language networks has also been shown in disorders such as autism spectrum disorder and schizophrenia (Mitchell and Crow, 2005; Preslar et al., 2014). We speculate that the atypical functional lateralization of verbal fluency networks seen here could contribute to the increased psychiatric risk in very preterm samples (Nosarti et al., 2012).

While not demonstrating a significant association between right STG and right sensorimotor cortex hemodynamic response and the AF seen in controls, very preterm adults instead showed a distinct relationship between increased right STG hemodynamic response suppression during hard letter trials and higher left FAT HMOA. This finding is consistent with other studies proposing that the FAT plays a role in verbal fluency processing in clinical populations (Catani et al., 2013; Kronfeld-Duenias et al., 2016). Together with the previously discussed findings, our results suggest a remapping of the neuroanatomical underpinnings of verbal fluency to prioritize the left FAT in very preterm adults. However, as neither left FAT HMOA nor right STG hemodynamic response showed a significant association with on-line task performance, with the current results we are unable to determine if this observed structural-functional association may be adaptive or maladaptive. Another interpretation for our unique withingroup results could be that the two tracts we investigated, the AF and the FAT, which are differentially involved in various aspects of language (Catani and Bambini, 2014), may be supporting distinct linguistic operations in controls and very preterm adults. It was not within the scope of this study to carry out an extensive assessment of language processing and further studies are needed to pinpoint the specific functions of each tract in typically and atypically developing samples.

\section{Brain lateralization and language}

So far in the reviewed literature, left-lateralization of the brain has been associated with better language skills. However, previous studies have also reported no relationship between functional brain lateralization and language skills in healthy subjects (Knecht et al., 2001), but in those with developmental difficulties (Illingworth and Bishop, 2009). It is possible that atypical cerebral lateralization is a potential risk factor for language impairment and the addition of or interaction with other factors (e.g., genetic) may be the cause of language difficulties (Bishop, 2013). It is worth highlighting that cerebral lateralization can change throughout development and may be a consequence rather than a cause of poor language abilities (Bishop, 2013).

\section{Sex differences within the very preterm group}

Contrary to previous findings that preterm girls outperform boys on language skills (Eriksson et al., 2012), this study found that very preterm men performed better than women on the easy letters during the verbal fluency task and had higher verbal IQ. However, in the larger sample the current participants were drawn from (Kroll et al., 2017), there were no sex differences in verbal IQ. Future studies with larger sample sizes are needed to confirm whether there are sex differences in language abilities in very preterm adults.

\section{Limitations}

We acknowledge that there are several limitations to this study. The nature of verbal fluency, being a combined measure of verbal and executive function abilities, makes it difficult to tease out which cognitive component may be affected in a specific population sample. This study selectively focused on the language component of the task. The executive function component of verbal fluency and corresponding white matter connections, which may explain other aspects of the long-term sequelae of very preterm birth, remains an area to explore further.

Very preterm adults in this study only showed lower verbal and not performance IQ compared to controls, although in the larger sample they were drawn from, they had lower verbal and performance IQ (Kroll et al., 2017). In this study, we found that poorer verbal IQ was associated with worse verbal fluency on the hard letter trials in the very preterm group only, suggesting that verbal fluency may represent one of the various aspects of language processing that may be affected by very preterm birth, although not assessed here.

There are a number of potential methodological limitations. First, is the exclusive consideration of white matter fiber tracts that we thought to be involved in verbal fluency. Therefore, we did not investigate other tracts, such the uncinate fasciculus, which enables the mapping of sound to meaning and is viewed as a critical component of the language network (Friederici and Gierhan, 2013), yet has not been directly implicated in letter fluency (Catani et al., 2013; Kljajevic et al., 2016). Second, there is a concern that false positive rates of $\mathrm{fMRl}$ findings using parametric statistical methods with cluster-based inference is higher than anticipated (Eklund et al., 2016). There is currently no non-parametric equivalent of FEAT's FLAME to assess differences in findings between parametric and nonparametric methods. Therefore, the results reported in this study should be interpreted with caution and future work to validate these findings with nonparametric methods is needed.

\section{Conclusion}

Very preterm adults exhibited worse verbal fluency performance than controls when a high cognitive demand 
was required. The results of this study suggest that this may be due to deviations in typical development, resulting in a less left-lateralized network underlying verbal fluency. Verbal fluency processing in very preterm adults may be supported by a potential remapping of structuralfunctional brain associations, involving the FAT. Based on this study, future work is warranted to explore the development of brain lateralization in very preterm individuals at different stages of maturation.

\section{References}

Aarnoudse-Moens CSH, Weisglas-Kuperus N, van Goudoever JB, Oosterlaan J (2009) Meta-analysis of neurobehavioral outcomes in very preterm and/or very low birth weight children. Pediatrics 124:717-728.

Andersson J, Jenkinson M, Smith S (2010) Non-linear registration, aka spatial normalisation. FMRIB technical report TR07JA2.

Annett M (1967) The binomial distribution of right, mixed and left handedness. Q J Exp Psychol 19:327-333.

Annoni JM, Khateb A, Gramigna S, Staub F, Carota A, Maeder P, Bogousslavsky J (2003) Chronic cognitive impairment following laterothalamic infarcts: a study of 9 cases. Arch Neurol 60:14391443.

Ardila A, Bernal B, Rosselli M (2014) Participation of the insula in language revisited: a meta-analytic connectivity study. J Neurolinguistics 29:31-41.

Ball G, Pazderova L, Chew A, Tusor N, Merchant N, Arichi T, Allsop JM, Cowan FM, Edwards AD, Counsell SJ (2015) Thalamocortical connectivity predicts cognition in children born preterm. Cereb Cortex 25:4310-4318.

Barde LH, Yeatman JD, Lee ES, Glover G, Feldman HM (2012) Differences in neural activation between preterm and full term born adolescents on a sentence comprehension task: implications for educational accommodations. Dev Cogn Neurosci 2 [Suppl 1]: S114-S128.

Benjamini Y, Hochberg Y (1995) Controlling the false discovery rate - a practical and powerful approach to multiple testing. J R Stat Soc Series B Stat Methodol 57:289-300.

Birn RM, Kenworthy L, Case L, Caravella R, Jones TB, Bandettini PA, Martin A (2010) Neural systems supporting lexical search guided by letter and semantic category cues: a self-paced overt response fMRI study of verbal fluency. Neuroimage 49:1099-1107.

Bishop DV (2013) Cerebral asymmetry and language development: cause, correlate, or consequence? Science 340:1230531.

Boardman JP, Counsell SJ, Rueckert D, Kapellou O, Bhatia KK, Aljabar P, Hajnal J, Allsop JM, Rutherford MA, Edwards AD (2006) Abnormal deep grey matter development following preterm birth detected using deformation-based morphometry. Neuroimage 32: 70-78.

Caldinelli C, Froudist-Walsh S, Karolis V, Tseng CE, Allin MP, Walshe M, Cuddy M, Murray RM, Nosarti C (2017) White matter alterations to cingulum and fornix following very preterm birth and their relationship with cognitive functions. Neuroimage 150:373-382.

Catani M, Thiebaut de Schotten M (2008) A diffusion tensor imaging tractography atlas for virtual in vivo dissections. Cortex 44:11051132.

Catani M, Bambini V (2014) A model for social communication and language evolution and development (SCALED). Curr Opin Neurobiol 28:165-171.

Catani M, Dell'acqua F, Vergani F, Malik F, Hodge H, Roy P, Valabregue $R$, Thiebaut de Schotten $M$ (2012) Short frontal lobe connections of the human brain. Cortex 48:273-291.

Catani M, Mesulam MM, Jakobsen E, Malik F, Martersteck A, Wieneke C, Thompson CK, Thiebaut de Schotten M, Dell'Acqua F, Weintraub S, Rogalski E (2013) A novel frontal pathway underlies verbal fluency in primary progressive aphasia. Brain 136:26192628.
Chang LJ, Yarkoni T, Khaw MW, Sanfey AG (2013) Decoding the role of the insula in human cognition: functional parcellation and largescale reverse inference. Cereb Cortex 23:739-749.

Dehaene-Lambertz G, Hertz-Pannier L, Dubois J (2006a) Nature and nurture in language acquisition: anatomical and functional brainimaging studies in infants. Trends Neurosci 29:367-373.

Dehaene-Lambertz G, Hertz-Pannier L, Dubois J, Meriaux S, Roche A, Sigman M, Dehaene S (2006b) Functional organization of perisylvian activation during presentation of sentences in preverbal infants. Proc Natl Acad Sci USA 103:14240-14245.

Dell'acqua F, Scifo P, Rizzo G, Catani M, Simmons A, Scotti G, Fazio $F$ (2010) A modified damped Richardson-Lucy algorithm to reduce isotropic background effects in spherical deconvolution. Neuroimage 49:1446-1458.

Dell'Acqua F, Simmons A, Williams SCR, Catani M (2013) Can spherical deconvolution provide more information than fiber orientations? Hindrance modulated orientational anisotropy, a truetract specific index to characterize white matter diffusion. Hum Brain Mapp 34:2464-2483.

Dick AS, Tremblay P (2012) Beyond the arcuate fasciculus: consensus and controversy in the connectional anatomy of language. Brain 135:3529-3550.

Dubois J, Hertz-Pannier L, Cachia A, Mangin JF, Le Bihan D, DehaeneLambertz G (2009) Structural asymmetries in the infant language and sensorimotor networks. Cereb Cortex 19:414-423.

Eklund A, Nichols TE, Knutsson H (2016) Cluster failure: why fMRI inferences for spatial extent have inflated false-positive rates. Proc Natl Acad Sci USA 113:7900-7905.

Eriksson M, Marschik PB, Tulviste T, Almgren M, Pérez Pereira M, Wehberg S, Marjanovič-Umek L, Gayraud F, Kovacevic M, Gallego C (2012) Differences between girls and boys in emerging language skills: evidence from 10 language communities. Br J Dev Psychol 30:326-343.

Feldman HM, Lee ES, Yeatman JD, Yeom KW (2012) Language and reading skills in school-aged children and adolescents born preterm are associated with white matter properties on diffusion tensor imaging. Neuropsychologia 50:3348-3362.

Friederici AD, Gierhan SM (2013) The language network. Curr Opin Neurobiol 23:250-254.

Friederici AD, Brauer J, Lohmann G (2011) Maturation of the language network: from inter- to intrahemispheric connectivities. PLoS One 6:e20726.

Frith CD, Friston KJ, Liddle PF, Frackowiak RS (1991) A PET study of word finding. Neuropsychologia 29:1137-1148.

Froudist-Walsh S, Karolis V, Caldinelli C, Brittain PJ, Kroll J, Rodriguez-Toscano $E$, Tesse $M$, Colquhoun M, Howes $O$, Dell'Acqua F, de Schotten MT, Murray RM, Williams SCR, Nosarti C (2015) Very early brain damage leads to remodeling of the working memory system in adulthood: a combined $\mathrm{fMRI} /$ tractography study. J Neurosci 35:15787-15799.

Fu CHY, Morgan K, Suckling J, Williams SCR, Andrew C, Vythelingum GN, McGuire PK (2002) A functional magnetic resonance imaging study of overt letter verbal fluency using a clustered acquisition sequence: greater anterior cingulate activation with increased task demand. Neuroimage 17:871-879.

Gimenez M, Junque C, Narberhaus A, Botet F, Bargallo N, Mercader JM (2006) Correlations of thalamic reductions with verbal fluency impairment in those born prematurely. Neuroreport 17:463-466.

Glasser MF, Rilling JK (2008) DTI tractography of the human brain's language pathways. Cereb Cortex 18:2471-2482.

Gozzo Y, Vohr B, Lacadie C, Hampson M, Katz KH, MallerKesselman J, Schneider KC, Peterson BS, Rajeevan N, Makuch RW, Constable RT, Ment LR (2009) Alterations in neural connectivity in preterm children at school age. Neuroimage 48:458-463.

Greve DN, Fischl B (2009) Accurate and robust brain image alignment using boundary-based registration. Neuroimage 48:63-72.

Griffanti L, Salimi-Khorshidi G, Beckmann CF, Auerbach EJ, Douaud G, Sexton CE, Zsoldos E, Ebmeier KP, Filippini N, Mackay CE, Moeller S, Xu J, Yacoub E, Baselli G, Ugurbil K, Miller KL, Smith SM (2014) ICA-based artefact removal and accelerated fMRI ac- 
quisition for improved resting state network imaging. Neuroimage 95:232-247.

Habas PA, Scott JA, Roosta A, Rajagopalan V, Kim K, Rousseau F, Barkovich AJ, Glenn OA, Studholme C (2012) Early folding patterns and asymmetries of the normal human brain detected from in utero MRI. Cereb Cortex 22:13-25.

Her Majesty's Stationary Office (1991) Office of population censuses and surveys, standard occupational classification. London: HMSO.

Hickok G, Poeppel D (2007) The cortical organization of speech processing. Nat Rev Neurosci 8:393-402.

Hickok G, Buchsbaum B, Humphries C, Muftuler T (2003) Auditorymotor interaction revealed by $\mathrm{fMRI}$ : speech, music, and working memory in area Spt. J Cogn Neurosci 15:673-682.

Hickok G, Okada K, Serences JT (2009) Area Spt in the human planum temporale supports sensory-motor integration for speech processing. J Neurophysiol 101:2725-2732.

Holland SK, Vannest J, Mecoli M, Jacola LM, Tillema JM, Karunanayaka PR, Schmithorst VJ, Yuan W, Plante E, Byars AW (2007) Functional MRI of language lateralization during development in children. Int J Audiol 46:533-551.

Hüppi PS, Warfield S, Kikinis R, Barnes PD, Zientara GP, Jolesz FA, Tsuji MK, Volpe JJ (1998) Quantitative magnetic resonance imaging of brain development in premature and mature newborns. Ann Neurol 43:224-235.

Illingworth S, Bishop DV (2009) Atypical cerebral lateralisation in adults with compensated developmental dyslexia demonstrated using functional transcranial Doppler ultrasound. Brain Lang 111: $61-65$.

Jenkinson M, Smith S (2001) A global optimisation method for robust affine registration of brain images. Med Image Anal 5:143-156.

Jenkinson M, Bannister P, Brady M, Smith S (2002) Improved optimization for the robust and accurate linear registration and motion correction of brain images. Neuroimage 17:825-841.

Just MA, Varma S (2007) The organization of thinking: what functional brain imaging reveals about the neuroarchitecture of complex cognition. Cogn Affect Behav Neurosci 7:153-191.

Kalpakidou AK, Allin MPG, Walshe M, Giampietro V, McGuire PK, Rifkin L, Murray RM, Nosarti C (2014) Functional neuroanatomy of executive function after neonatal brain injury in adults who were born very preterm. PLoS One 9:e113975.

Karolis VR, Froudist-Walsh S, Brittain PJ, Kroll J, Ball G, Edwards AD, Dell'Acqua F, Williams SC, Murray RM, Nosarti C (2016) Reinforcement of the brain's rich-club architecture following early neurodevelopmental disruption caused by very preterm birth. Cereb Cortex 26:1322-1335.

Kasprian G, Langs G, Brugger PC, Bittner M, Weber M, Arantes M, Prayer D (2011) The prenatal origin of hemispheric asymmetry: an in utero neuroimaging study. Cereb Cortex 21:1076-1083.

Kelly RE Jr, Alexopoulos GS, Wang Z, Gunning FM, Murphy CF, Morimoto SS, Kanellopoulos D, Jia Z, Lim KO, Hoptman MJ (2010) Visual inspection of independent components: defining a procedure for artifact removal from fMRI data. J Neurosci Methods 189:233-245.

Kljajevic V, Dyrba M, Kasper E, Teipel S (2016) Is the left uncinate fasciculus associated with verbal fluency decline in mild Alzheimer's disease? Transl Neurosci 7:89-91.

Klostermann F, Krugel LK, Ehlen F (2013) Functional roles of the thalamus for language capacities. Front Syst Neurosci 7:32.

Knecht S, Dräger B, Deppe M, Bobe L, Lohmann H, Flöel A, Ringelstein EB, Henningsen $H(2000)$ Handedness and hemispheric language dominance in healthy humans. Brain 123:2512-2518.

Knecht S, Drager B, Floel A, Lohmann H, Breitenstein C, Deppe M, Henningsen H, Ringelstein EB (2001) Behavioural relevance of atypical language lateralization in healthy subjects. Brain 124: $1657-1665$.

Kostovíc I, Jovanov-Milosevíc N (2006) The development of cerebral connections during the first 20-45 weeks' gestation. Semin Fetal Neonatal Med 11:415-422.
Kroll J, Karolis V, Brittain PJ, Tseng CJ, Froudist-Walsh S, Murray RM, Nosarti C (2017) Real-life impact of executive function impairments in adults who were born very preterm. $\mathrm{J}$ Int Neuropsychol Soc 23:381-389.

Kronfeld-Duenias V, Amir O, Ezrati-Vinacour R, Civier O, BenShachar M (2016) The frontal aslant tract underlies speech fluency in persistent developmental stuttering. Brain Struct Funct 221: 365-381.

Kwon SH, Scheinost D, Lacadie C, Sze G, Schneider KC, Dai F, Constable RT, Ment LR (2015) Adaptive mechanisms of developing brain: cerebral lateralization in the prematurely-born. Neuroimage 108:144-150.

Leemans A, Jones DK (2009) The B-matrix must be rotated when correcting for subject motion in DTI data. Magn Reson Med 61: 1336-1349.

Leemans A, Sijbers J, Jones DK (2009) ExploreDTI: a graphical toolbox for processing, analyzing, and visualizing diffusion MR data. Proc Intl Soc Mag Reson Med 17:3537.

Liebenthal E, Binder JR, Spitzer SM, Possing ET, Medler DA (2005) Neural substrates of phonemic perception. Cereb Cortex 15:16211631.

Luu TM, Vohr BR, Allan W, Schneider KC, Ment LR (2011) Evidence for catch-up in cognition and receptive vocabulary among adolescents born very preterm. Pediatrics 128:313-322.

Mitchell RL, Crow TJ (2005) Right hemisphere language functions and schizophrenia: the forgotten hemisphere? Brain 128:963-978.

Mullen KM, Vohr BR, Katz KH, Schneider KC, Lacadie C, Hampson M, Makuch RW, Reiss AL, Constable RT, Ment LR (2011) Preterm birth results in alterations in neural connectivity at age 16 years. Neuroimage 54:2563-2570.

Myers EH, Hampson M, Vohr B, Lacadie C, Frost SJ, Pugh KR, Katz KH, Schneider KC, Makuch RW, Constable RT, Ment LR (2010) Functional connectivity to a right hemisphere language center in prematurely born adolescents. Neuroimage 51:1445-1452.

Nam KW, Castellanos N, Simmons A, Froudist-Walsh S, Allin MP, Walshe M, Murray RM, Evans A, Muehlboeck JS, Nosarti C (2015) Alterations in cortical thickness development in preterm-born individuals: implications for high-order cognitive functions. Neuroimage 115:64-75.

Nosarti C, Shergill SS, Allin MP, Walshe M, Rifkin L, Murray RM, McGuire PK (2009) Neural substrates of letter fluency processing in young adults who were born very preterm: alterations in frontal and striatal regions. Neuroimage 47:1904-1913.

Nosarti C, Reichenberg A, Murray RM, Cnattingius S, Lambe MP, Yin L, MacCabe J, Rifkin L, Hultman CM (2012) Preterm birth and psychiatric disorders in young adult life. Arch Gen Psychiatry 69:610-617.

Nosarti C, Nam KW, Walshe M, Murray RM, Cuddy M, Rifkin L, Allin MPG (2014) Preterm birth and structural brain alterations in early adulthood. Neuroimage Clin 6:180-191.

Petanjek Z, Judaš M, Šimic G, Rasin MR, Uylings HBM, Rakic P, Kostovic I (2011) Extraordinary neoteny of synaptic spines in the human prefrontal cortex. Proc Natl Acad Sci USA 108:1328113286.

Phillips JS, Greenberg AS, Pyles JA, Pathak SK, Behrmann M, Schneider W, Tarr MJ (2012) Co-analysis of brain structure and function using fMRI and diffusion-weighted imaging. J Vis Exp. Advance online publication. Retrieved November 8, 2012. doi: 10.3791/4125.

Preslar J, Kushner HI, Marino L, Pearce B (2014) Autism, lateralisation, and handedness: a review of the literature and meta-analysis. Laterality 19:64-95.

Pulvermuller F (2005) Brain mechanisms linking language and action. Nat Rev Neurosci 6:576-582.

Pulvermuller F, Fadiga L (2010) Active perception: sensorimotor circuits as a cortical basis for language. Nat Rev Neurosci 11:351360.

Ravnkilde B, Videbech P, Rosenberg R, Gjedde A, Gade A (2002) Putative tests of frontal lobe function: a PET-study of brain acti- 
vation during Stroop's test and verbal fluency. J Clin Exp Neuropsychol 24:534-547.

Salimi-Khorshidi G, Douaud G, Beckmann CF, Glasser MF, Griffanti L, Smith SM (2014) Automatic denoising of functional MRI data: combining independent component analysis and hierarchical fusion of classifiers. Neuroimage 90:449-468.

Salvan P, Nosarti C (2018) Developments in diffusion MRI and tractography to study language network alterations following very preterm birth. F1000Research 7:1-7.

Sauzéon H, Lestage P, Raboutet C, N'Kaoua B, Claverie B (2004) Verbal fluency output in children aged $7-16$ as a function of the production criterion: qualitative analysis of clustering, switching processes, and semantic network exploitation. Brain Lang 89:192202.

Schafer RJ, Lacadie C, Vohr B, Kesler SR, Katz KH, Schneider KC, Pugh KR, Makuch RW, Reiss AL, Constable RT, Ment LR (2009) Alterations in functional connectivity for language in prematurely born adolescents. Brain 132:661-670.

Scheinost D, Lacadie C, Vohr BR, Schneider KC, Papademetris X, Constable RT, Ment LR (2015) Cerebral lateralization is protective in the very prematurely born. Cerebral. Cortex 25:1858-1866.

Seghier ML (2008) Laterality index in functional MRI: methodological issues. Magn Reson Imaging 26:594-601.

Skeide MA, Friederici AD (2016) The ontogeny of the cortical language network. Nat Rev Neurosci 17:323-332.

Smyser CD, Inder TE, Shimony JS, Hill JE, Degnan AJ, Snyder AZ, Neil JJ (2010) Longitudinal analysis of neural network development in preterm infants. Cereb Cortex 20:2852-2862.

Sowell ER, Thompson PM, Rex D, Kornsand D, Tessner KD, Jernigan TL, Toga AW (2002) Mapping sulcal pattern asymmetry and local cortical surface gray matter distribution in vivo: maturation in perisylvian cortices. Cereb Cortex 12:17-26.

Stewart AL, Thorburn RJ, Hope PL, Goldsmith M, Lipscomb AP, Reynolds EO (1983) Ultrasound appearance of the brain in very preterm infants and neurodevelopmental outcome at 18 months of age. Arch Dis Child 58:598-604.

Tomasi D, Ernst T, Caparelli EC, Chang L (2006) Common deactivation patterns during working memory and visual attention tasks: an intra-subject fMRI study at 4 Tesla. Hum Brain Mapp 27:694-705.

Tomasi D, Wang R, Wang GJ, Volkow ND (2014) Functional connectivity and brain activation: a synergistic approach. Cereb Cortex 24:2619-2629.

Tournier JD, Calamante F, Gadian DG, Connelly A (2004) Direct estimation of the fiber orientation density function from diffusionweighted MRI data using spherical deconvolution. Neuroimage 23:1176-1185

Tseng CJ, Froudist-Walsh S, Brittain PJ, Karolis V, Caldinelli C, Kroll J, Counsell SJ, Williams SC, Murray RM, Nosarti C (2017) A multimodal imaging study of recognition memory in very preterm born adults. Hum Brain Mapp 38:644-655.

Turkeltaub PE, Coslett HB, Thomas AL, Faseyitan O, Benson J, Norise C, Hamilton RH (2012) The right hemisphere is not unitary in its role in aphasia recovery. Cortex 48:1179-1186.

Volpe JJ (2009) Brain injury in premature infants: a complex amalgam of destructive and developmental disturbances. Lancet Neurol 8:110-124.

Wechsler D (1999) Wechsler abbreviated scale of intelligence (WASI). New York: The Psychological Corporation.

Wilkins B, Lee N, Gajawelli N, Law M, Leporé N (2015) Fiber estimation and tractography in diffusion MRI: development of simulated brain images and comparison of multi-fiber analysis methods at clinical b-values. Neuroimage 109:341-356.

Yeatman JD, Rauschecker AM, Wandell BA (2013) Anatomy of the visual word form area: adjacent cortical circuits and long-range white matter connections. Brain Lang 125:146-155.

Yeatman JD, Weiner KS, Pestilli F, Rokem A, Mezer A, Wandell BA (2014) The vertical occipital fasciculus: a century of controversy resolved by in vivo measurements. Proc Natl Acad Sci USA 111: E5214-E5223. 